\title{
RELEVÂNCIA E APLICABILIDADE DA PESQUISA EM EDUCAÇÃO
}

\author{
ALDA JUDITH ALVES-MAZZOTTI \\ Faculdade de Educação da Universidade Estácio de Sá. \\ aldamazzotti@imagelink.com.br
}

\begin{abstract}
RESUMO
Partindo das principais avaliações da qualidade da pesquisa em educação, o artigo sustenta que todas as deficiências observadas são, ao mesmo tempo, decorrentes e realimentadoras da pobreza teórico-metodológica apontada nessas pesquisas. A seguir, procura-se demonstrar a importância da teorização sobre os resultados para favorecer a transferibilidade para outras pesquisas dos conhecimentos produzidos, o que, por sua vez, facilita sua divulgação e avaliação pela comunidade científica. Enfatiza-se finalmente que a identificação de padrões, dimensões e relaçâes, ou mesmo a construção de modelos explicativos, além de não ser incompatível com o estudo de fenômenos microssociais, constitui etapa essencial à construção da teoria e à aplicação a outros contextos.

AVALIAÇÃO DA EDUCAÇÃO - PESQUISA EDUCACIONAL
\end{abstract}

\begin{abstract}
RELEVANCE AND APPLICABILITY OF EDUCATIONAL RESEARCH. Based on encompassing evaluations of educational research, the article sustains that all the deficiencies mentioned are both consequent and determinant of the poor theory/method approach presented by that research. The importance of theorization is emphasized as a mean of fostering transferibility of the knowledge produced, which, by its turn, facilitates its diffusion among practitioners and its evaluation by the scientific community. Finally, it is sustained that the identification of patterns, dimensions and relations, or even the construction of explicative models, is not only compatible with the study of micro-social phenomena, but also constitutes an essential step in the construction of theory and in its application to other contexts.
\end{abstract}




\section{INTRODUÇÃO}

A discussão sobre a qualidade da pesquisa em educação no Brasil já tem uma longa história. Dentre as análises disponíveis em publicações nacionais, encontra-se número significativo de avaliações sistemáticas que buscam oferecer um panorama abrangente da pesquisa nessa área. Exemplos desse tipo de estudo são os trabalhos de Gouveia (1971 , 1976), que examinam a pesquisa educacional desde seu início como atividade regular, com a criação do Inep em 1938, até a década de 70; o trabalho de Gatti ( 1983), que estende a análise até 1982; e as resultantes do projeto "Avaliação e perspectivas na área de educação" (Associação Nacional de Pós-Graduação e Pesquisa em Educação - ANPEd, 1993), que cobre o período de 1982 a 1991. Outras análises, ainda que se dediquem a aspectos mais específicos, tornaram-se referências obrigatórias, como, por exemplo, os de Cunha (1979, 1991), Mello (1983) e Warde (1990).

Tais avaliações têm focalizado aspectos relativos tanto aos processos de produção das pesquisas quanto aos produtos, incluindo pesquisas docentes e discentes, com a utilização de abordagens quantitativas e qualitativas. Quanto ao processo de produção da pesquisa, foram destacados os seguintes problemas: (a) primazia do ensino sobre a pesquisa no âmbito das universidades, deixando aos docentes pesquisadores pouca disponibilidade de tempo para a pesquisa e a orientação; (b) quase ausência de equipes com articulação e continuidade suficientes para o estabelecimento de linhas de investigação que favoreçam a produção de um corpo sólido e integrado de conhecimentos e confiram um perfil próprio aos diferentes programas de pós-graduação; e (c) falta de apoio efetivo das universidades e das agências de fomento ao desenvolvimento de pesquisas.

No que se refere às deficiências apontadas nas pesquisas produzidas, destacam-se: (a) pobreza teórico-metodológica na abordagem dos temas, com um grande número de estudos puramente descritivos e/ou "exploratórios"; (b) pulverização e irrelevância dos temas escolhidos; (c) adoção acrítica de modismos na seleção de quadros teórico-metodológicos; (d) preocupação com a aplicabilidade imediata dos resultados; e (e) divulgação restrita dos resultados e pouco impacto sobre as práticas.

Avaliações, em quantidade e qualidade reconhecidas, portanto, não nos faltam. Infelizmente, porém, não estamos nos beneficiando suficientemente dos resultados desse esforço, uma vez que essas deficiências, reiteradamente apontadas, persistem até hoje.

Nos comentários que se seguem, examino alguns aspectos que me parecem favorecer a persistência desses problemas, no que se refere especificamente à pro- 
dução de dissertações e teses, procurando enfatizar o papel dos docentes e orientadores que atuam nos cursos de pós-graduação. A preocupação com o aprimoramento das teses e dissertações é justificada, não apenas pelo fato de que delas se originou a quase totalidade de livros e artigos que constituem a bibliografia recente no campo da educação (Cunha, |99|), mas principalmente porque elas representam um importante indicador da qualidade dos pesquisadores que estamos formando. Por outro lado, a ênfase no papel dos docentes que atuam na pós-graduação se deve ao fato de que nossa responsabilidade nesse processo não tem, no meu entender, recebido a atenção necessária nessa discussão.

\section{A CENTRALIDADE DA QUESTÃO TEÓRICO-METODOLÓGICA}

Todas as deficiências apontadas pelas avaliações mencionadas estão, a meu ver, inter-relacionadas. Assim, a pobreza teórico-metodológica identificada nas pesquisas parece ser, em grande parte, responsável pela sua pulverização e irrelevância e, também, pela adesão aos modismos e pela preocupação com a aplicabilidade imediata dos resultados. Em outras palavras, o desconhecimento das discussões teórico-metodológicas travadas na área leva muitos pesquisadores iniciantes, principalmente os alunos de mestrado, a permanecerem "colados" em sua própria prática, dela derivando o seu problema de pesquisa e a ela buscando retornar com aplicações imediatas dos resultados obtidos'. O fato de que esses estudos costumam ser restritos a uma situação muito específica e de que a teorização se encontra ausente ou é insuficiente para que possa ser aplicada ao estudo de situações semeIhantes resulta na pulverização e na irrelevância desses estudos. Por outro lado, a pouca atenção dada ao conhecimento acumulado na área, ao não permitir uma análise mais consistente dos referenciais conceituais disponíveis para a abordagem do tema de interesse, favorece a adesão acrítica a autores "da moda". Finalmente, o pouco interesse que tais estudos despertam, pelas características anteriormente apontadas, explica sua restritíssima divulgação e seu pouco impacto na prática educacional considerada de maneira mais ampla². Podemos concluir que todas as defi-

I. Não se está aqui criticando o fato de se desenvolver uma pesquisa a partir de dificuldades encontradas na prática. Na realidade, muitas pesquisas pecam exatamente por seu completo distanciamento dos problemas com que se defrontam os professores no cotidiano das salas de aula. Mas se o pesquisador permanece no nível de sua prática específica e de seus interesses individuais, sem uma tentativa de teorização que permita estender suas reflexões a outras situações, pouco ou nada contribui para a construção de conhecimentos relevantes.

2. Para uma análise do pouco impacto da pesquisa educacional na prática, ver Kennedy ( 1997 ). 
ciências mencionadas são, ao mesmo tempo, decorrentes e realimentadoras da pobreza teórico-metodológica apontada nas pesquisas em educação.

\section{TEORIZAÇÃO E TRANSFERIBILIDADE DO CONHECIMENTO}

Decorrida uma década da última avaliação de larga escala mencionada, esses problemas ainda persistem e alguns deles parecem ter-se agravado. De fato, em congressos dos quais tive a oportunidade de participar e em projetos e relatórios que analisei como parecerista de agências de fomento, assim como em bancas de dissertações e teses de que participei ao longo desta última década, tenho observado que muitas das pesquisas atuais na área de educação parecem, cada vez mais, desconsiderar que a produção do conhecimento científico constitui um processo de construção coletiva. Um indicador bastante concreto disso é a despreocupação, cada vez maior, nos projetos e relatórios de pesquisa, de situar o problema proposto no contexto mais amplo da discussão acadêmica sobre o tema focalizado. Isso se verifica tanto pela falta de uma introdução que proporcione um "pano de fundo" às questões focalizadas quanto pela ausência de comparações entre os resultados obtidos e aqueles originados por outros estudos relacionados ao tema, ou, ainda, entre os resultados e as implicações de alguma teoria. Nesses casos, a impressão que se tem é a de que o conhecimento sobre o problema começou e terminou com aquela investigação, configurando uma espécie de "narcisismo investigativo" (Alves-Mazzotti, Gewandsznajder, 1999). Ao não situar o problema na discussão mais ampla sobre o tema focalizado, o pesquisador reduz a questão estudada ao recorte de seu próprio estudo, restringindo, assim, o número de interessados em seus resultados, o que contribui decisivamente para dificultar sua divulgação.

Quando enfatizo a importância dessa contextualização do problema por meio do diálogo com estudos anteriores, não me refiro à "revisão da bibliografia", que arrola autores e mais autores, usando a fórmula burocrática " segundo fulano", "para beltrano", deixando de fora o autor da pesquisa e não evidenciando sua funcionalidade na discussão dos resultados. Quando falo em diálogo, refiro-me à comparação e à crítica que explicitam inicialmente a necessidade e pertinência do estudo proposto, e, ao seu final, apontam corroborações e discordâncias entre os resultados obtidos e os estudos anteriores. Tais procedimentos não são formalismos acadêmicos, são condições necessárias à cumulatividade e transferibilidade do conhecimento, assim como à formulação de teorias.

Sabemos que os paradigmas diferem entre si quanto à utilização de teorias. Os argumentos usados para defender cada uma das posições são coerentes com 
as raízes epistemológicas dos paradigmas que as propõem. Os construcionistas sociais, por exemplo, defendem a não-utilização de teorias a priori, preferindo que a teorização surja da análise dos dados. Argumentam que, dada a natureza idiográfica e holística dos fenômenos sociais, nenhuma teoria previamente selecionada é capaz de dar conta dos significados dessa realidade tanto do ponto de vista específico como global. Além disso, consideram que a adoção de um quadro teórico anteriormente à coleta de dados turva a visão do pesquisador, levando-o a desconsiderar aspectos importantes que não se encaixam na teoria (Lincoln, Gubba, 1985). Já os pós-positivistas, e também muitos teórico-críticos, valorizam a utilização da teoria para a formulação de hipóteses e para a identificação de categorias de análise. Argumentam que dificilmente um pesquisador inicia sua coleta de dados sem que alguma teoria esteja orientando seus passos, mesmo que implicitamente, e, nesse caso, é preferível torná-la pública. Alertam, ainda, que a ausência de focalização e de critérios na coleta de dados freqüentemente resulta em perda de tempo, excesso de dados e dificuldade de interpretação (Marshall, Rossman, 1989; Milles, Huberman, 1984).

Argumentos de ambos os lados podem ser considerados válidos dependendo da situação estudada: a não-utilização de teorias a priorijustifica-se no estudo de situações pouco conhecidas. Se, entretanto, o pesquisador está lidando com um fenômeno sobre o qual já existe conhecimento acumulado por outras pesquisas realizadas em contexto semelhante, a utilização de um referencial teórico, seja ele uma teoria mais ampla ou um ou mais constructos teóricos, ajuda a focalizar as hipóteses e/ou questões a serem investigadas e a analisar os dados, evitando que o pesquisador se perca em um emaranhado de informações das quais não conseguirá extrair qualquer significado. Mas, se a teoria pode estar ausente no projeto, nem mesmo os construcionistas sociais defendem sua ausência no produto final, uma vez que se espera que o pesquisador construa sua teorização fundamentada nos dados (grounded theory).

Entretanto, apesar da aparente valorização da teoria, o que temos visto é que muitas pesquisas, sob a alegação de "dar voz" aos sujeitos ou de valorizar as práticas, limitam-se a reproduzir falas e falas dos sujeitos, sem qualquer tentativa de identificar regularidades, relações e categorias e/ou se servir de um instrumental analítico capaz de organizar e dar sentido aos dados. A crescente valorização da prática e da subjetividade parece estar levando a uma tendência à reificação da prática e do sujeito, em prejuízo da construção de conhecimentos relevantes e do diálogo com os autores que já se ocuparam do tema. Aparentemente, para fugir ao 
equívoco de aceitar a teoria como verdade, cai-se no equívoco de transferir para os sujeitos a posse da verdade 3 .

Mas o que me parece mais grave é que esse tipo de pesquisa também não contribui nem para a transformação da vida dos sujeitos nem para a melhoria das práticas. De fato, "dar voz" ao sujeitos que foram de alguma forma excluídos do cenário é de pouca valia se não especulamos sobre como e por que essas vozes foram antes silenciadas. Da mesma forma, a melhoria de práticas que se têm mostrado ineficazes exige a identificação dos aspectos recorrentes, bem como dos fatores que os condicionam. A compreensão das subjetividades e das práticas requer que se busque relacioná-las às condições sociais em que foram produzidas, procurando ir além da mera descrição, contribuindo para o debate mais amplo e para a produção de conhecimentos que possam ser apropriados por outrem.

Igualmente preocupada com essas questões, Fonseca (1999), tomando especificamente a pesquisa etnográfica, procura mostrar que é possível chegar do particular ao geral, pela utilização de modelos $^{4}$ (que nada mais são do que uma forma de teorização). Afirma que, na visão antropológica, a ênfase no aspecto social das condutas, e também dos sentimentos, leva à procura de sistemas, de relações, que vão além dos casos individuais, o que não significa anular as subjetividades. Segundo a autora, por envolver um pequeno número de sujeitos e por insistir no contato pessoal do pesquisador com eles, o método etnográfico propicia o estudo da subjetividade, sem cair na "sacralização do indivíduo".

Posição semelhante é defendida por Yin (1984), ao tratar da generalização dos resultados em estudos de caso. Esse autor esclarece que nesse tipo de pesquisa, como nas abordagens qualitativas em geral, não se trabalha com amostras representativas segundo as quais se pretende generalizar automaticamente os resultados para o universo que, teoricamente, aquela amostra representa. Assim, as possibilidades de transferência ou de utilização das conclusões de um estudo para outro

3 Muitos dos problemas aqui assinalados referem-se à maneira pela qual a perspectiva pósmoderna foi apropriada pela pesquisa educacional. Constas (1998), em uma extensa revisão de estudos que adotam essa perspectiva, aponta como características desses trabalhos: a) a rejeição a grand theories; b) a utilização de um pequeno número de sujeitos; c) o primado da narrativa; d) a ambigüidade do discurso; e e) a recusa em oferecer conclusões.

4 Os termos teoria e modelo relacionam-se a processos construtivos que nos permitem descrever e explicar fenômenos observados. Esses termos, hoje freqüentemente usados como intercambiáveis, para Dellatre (1992) correspondem a noções distintas, segundo o maior grau de abstração da teoria, em comparação com o modelo, este geralmente mais específico, representando uma realidade concreta bem determinada. 
repousa sobre o que ele chama de generalização analítica. Yin ilustra essa posição com um estudo de Jane Jacobs intitulado "Morte e vida das grandes cidades americanas". Embora o estudo tome por base a cidade de Nova York, a autora parte desses dados para discutir aspectos teóricos mais amplos, como o papel das calçadas e dos parques, a necessidade de quarteirões pequenos, os processos de favelização e desfavelização, chegando à construção de uma teoria sobre planejamento urbano que pode ser aplicada a outras grandes cidades.

\section{TRANSFERIBILIDADE DO CONHECIMENTO E OBJETIVIDADE}

A produção de conhecimentos "transferíveis", isto é, conhecimentos que possam ser aplicados a outras realidades, não apenas contribui para a acumulação do conhecimento, mas também favorece a divulgação das pesquisas, uma questão que não pode ser minimizada, na medida em que constitui condição necessária à construção coletiva do conhecimento. Se insisto na responsabilidade do pesquisador em favorecer essa construção coletiva do conhecimento é porque, nesse ponto, concordo com Popper quando afirma que

A objetividade da ciência não é uma questão referente aos cientistas individuais e sim ao resultado social de sua crítica mútua, da divisão de trabalho hostil-amistosa entre os cientistas, de sua cooperação e também de sua competição. (1976, p.95)

Em outras palavras, a única objetividade a que podemos aspirar em nossas pesquisas é aquela que resulta da crítica interpares, uma vez que ela permite expor as tendenciosidades do pesquisador. Exatamente por ser intersubjetivo, esse processo tem condições de minimizar os vieses de cada pesquisador, decorrentes de sua experiência pessoal, inserção social e história. $\bigcirc$ uso do termo "objetivo", no que se refere a uma investigação, significa que esta atende a certos critérios de qualidade, a padrões de procedimentos, embora a objetividade não deva ser confundida com certeza ou verdade (Phillips, 1990). Em resumo, o que é crucial para a objetividade de qualquer pesquisa é a aceitação da "tradição crítica", isto é, do fato de que a investigação deve ser o mais possível aberta à análise, à crítica e ao questionamento da comunidade científica para que erros grosseiros e tendenciosidades do pesquisador possam ser eliminados.

Nesse ponto, gostaria de retomar uma questão levantada por Cunha ( $99 \mid$ ), com referência às bancas de teses e dissertações, uma vez que essa está diretamente vinculada àquela que acabamos de mencionar. Cunha atribui grande parte da responsabilidade pela baixa qualidade de muitos trabalhos desenvolvidos em nossas 
pós-graduações ao que ele denominou "populismo pedagógico" (p.65). Afirma que a significativa diversidade, em termos de formação, verificada entre os professores por ocasião da criação desses cursos, e também entre os alunos, transformou disciplinas que seriam básicas em meras "introduções, desenvolvidas no nível das respectivas disciplinas de graduação" (p.64), e nem sempre fazendo as devidas vinculações com a Educação. O fato teria levado a um sistema de "facilitário" que se evidencia nas bancas de dissertação e tese que, segundo o autor, se tornaram mais uma "ação entre amigos" (p. 66) do que propriamente bancas examinadoras, aprovando trabalhos que não mereceriam a "cidadania acadêmica" (p. 64).

A esta avaliação gostaria de acrescentar alguns comentários. Tenho observado, não apenas em bancas de teses e dissertações, mas em outras discussões acadêmicas entre pesquisadores da educação, que estes parecem evitar a crítica, a discordância, como se isso fosse uma forma de destruir o conhecimento produzido e não a forma de construí-lo. Uma evidência dessa atitude pode ser encontrada no referido texto de Cunha, em uma nota de rodapé, em que o autor declara:

Houve quem me alertasse para os possíveis usos que se poderiam fazer desta análise, especialmente contra os interesses da área nas agências de fomento. Não adotei tal cautela devido ao fato de que outras áreas também se criticam, além do que, os problemas aqui expostos não são totalmente desconhecidos fora do nosso âmbito. (p. 64)

Vale aqui acrescentar que as áreas do saber que mais progridem são aquelas que mais se expõem e que mais naturalmente aceitam a crítica mútua como prática essencial ao processo de produção de conhecimentos confiáveis. No caso das bancas de teses e dissertações, ao evitar a crítica do documento que supostamente deveria estar sendo avaliado, desperdiça-se uma oportunidade preciosa de aprimorar um trabalho que consumiu anos de dedicação do aluno e, freqüentemente, uma soma considerável de recursos públicos.

\section{O NECESSÁRIO RESGATE DA RELEVÂNCIA}

Analisando a questão da qualidade das pesquisas realizadas nos programas de pós-graduação em educação, Warde (1990) afirma que se ampliou tanto o conceito de pesquisa que hoje nele tudo cabe: "os folclores, os sensos comuns, os relatos de experiência (de preferência, a própria), para não computar os desabafos

emocionais e os cabotinismos" (p. 70). A autora tem razão quando assinala o esgarçamento do conceito de pesquisa. Entretanto, por não ser esse um problema 
circunscrito ao campo da pesquisa em educação nem ao nosso país, creio ser necessário analisá-lo no contexto mais amplo ao qual está vinculado.

A dificuldade atual de se definir o que constitui pesquisa está diretamente vinculada às mudanças verificadas na conceituação de ciência e de método científico, resultantes da crítica do paradigma positivista. A aplicação do modelo positivista às ciências sociais, foi, como sabemos, questionado por muitos filósofos e pesquisadores, sobretudo aqueles filiados à tradição interpretativista ou hermenêutica e ao marxismo. Objeções pertinentes, de ordem epistemológica, ética e política, foram, então, colocadas. Não cabe, aqui, discuti-las, mas apenas lembrar que esses questionamentos levaram muitos pesquisadores das ciências sociais a rejeitar a qualificação de "científicos" para os conhecimentos e métodos produzidos em suas respectivas áreas, por considerarem que "o método científico" não era adequado ao seu objeto de estudo.

Entretanto, progressos ocorridos na filosofia da ciência, bem como suas repercussões nos debates travados no âmbito específico das ciências e práticas sociais, modificaram substancialmente os conceitos de ciência e de método científico. Hoje sabemos que todas as tentativas de estabelecer critérios de demarcação para distinguir, inequivocamente, o que pode e o que não pode ser considerado ciência, falharam. Para complicar mais as coisas, entre as diversas correntes que constituem a filosofia da ciência contemporânea, não há uma definição consensual do que seja ciência (Alves-Mazzotti, Gewandsznajder, 1999).

A ausência de critérios de demarcação consensuais e o abandono da falsas certezas prometidas pelo modelo tradicional de ciência parecem ter trazido uma considerável desorientação aos pesquisadores, principalmente no campo das ciências humanas e sociais, o que, freqüentemente, descambou no vale-tudo. Se, de um lado, essa desorientação parece compreensível, de outro, vemos que o relativismo, que se alastra em nossa área, não tem contribuído para a construção de conhecimentos suficientemente relevantes e confiáveis para orientar políticas e práticas educacionais.

Nada impede, porém, que pesquisas no campo da educação possam ser rigorosas, atendendo assim aos requisitos da tradição científica. Aqueles que questionam essa posição parecem basear-se em uma definição muito estrita e ultrapassada de ciência, a qual implica necessariamente quantificação e aplicação do método hipotético-dedutivo, esquecendo-se que, mesmo nas ciências naturais, nunca houve um método único que fosse adotado por todos os cientistas, nem mesmo durante o período de hegemonia positivista. 
Cabe lembrar, ainda, que as conceituações de pesquisa científica encontradas nas ciências naturais, em suas diferentes faces, sempre decorreram da prática concreta dos cientistas, constituindo-se através de um processo de construção histórica. Assim, em um processo análogo, é perfeitamente legítimo construir, nas ciências sociais, uma idéia de cientificidade, que pode ser distinta da adotada nas ciências naturais e mais adequada à natureza dos fenômenos por elas estudados, sem contudo desprezar o rigor, como se este fosse uma seqüela positivista.

De fato, já contamos hoje, no campo das ciências sociais e da educação, com uma variedade de modelos próprios de investigação, bem como com certos critérios que servem tanto para orientar o desenvolvimento da pesquisa como para avaliar a confiabilidade de suas conclusões. Admitir que esses critérios são decorrentes de um acordo entre pesquisadores da área, em um dado momento histórico, em nada compromete sua utilidade e relevância.

\section{CONCLUSÃO}

O grande desafio com que nos defrontamos hoje é conseguir aliar a riqueza proporcionada pelo estudo em profundidade de fenômenos microssociais, contextualizados, à possibilidade de transferência de conhecimentos ou à geração de hipóteses para o estudo de outros contextos semelhantes. Proporcionar uma "descrição densa" dos contextos e sujeitos da pesquisa, embora seja importante, não nos parece ser suficiente para favorecer a transferibilidade dos conhecimentos produzidos. A identificação de padrões, dimensões e relações, ou mesmo a construção de modelos explicativos, não é incompatível com o estudo de fenômenos microssociais. Tais formas de elaboração do material empírico constituem etapas essenciais na construção teórica, favorecendo a transferibilidade e a acumulação do conhecimento sobre um dado fenômeno.

A aplicabilidade dos conhecimentos na área da educação depende do desenvolvimento de teorias próprias, da seleção adequada de procedimentos e instrumentos, da análise interpretativa dos dados, de sua organização em padrões significativos, da comunicação precisa dos resultados e conclusões e da sua validação pela análise crítica da comunidade científica.

Os problemas a serem enfrentados no campo da educação, em nosso país, exigem soluções que precisam ser subsidiadas por um corpo de conhecimentos significativamente mais amplo e mais confiável do que aquele que estamos produzindo. Não desconhecemos os obstáculos que dificultam o desempenho dessa tarefa, dos epistemológicos aos institucionais. Mas nossa responsabilidade como pes- 
quisadores e como professores de programas de pós-graduação não pode ser minimizada. Não podemos abrir mão do compromisso com a produção de conhecimentos confiáveis, pois só assim estaremos contribuindo, tanto para desenvolver o instrumental teórico no campo da educação como para favorecer tomadas de decisão mais eficazes, substituindo as improvisações e os modismos que têm guiado as ações em nossa área. Nesse sentido, a busca da relevância e do rigor nas pesquisas é também uma meta política.

\section{REFERÊNCIAS BIBLIOGRÁFICAS}

ALVES-MAZZOTTI, A. J.; GEWANDSZNAJDER, F. O Método nas ciências naturais e sociais. pesquisa quantitativa e qualitativa. 2. ed. São Paulo: Pioneira, 1999.

ASSOCIAÇÃO NACIONAL DE PÓS-GRADUAÇÃO E PESQUISA EM EDUCAÇÃO. Avaliação e perspectivas na área de educação: 1982-1991. Porto Alegre: ANPEd, 1993.

BRUYNE, P.; HERMAN, J.; SCHOUTHEETE, M. Dinâmica da pesquisa em ciências sociais. Rio de Janeiro: Livraria Francisco Alves Editora, 1977.

CONSTAS, M. A. The Changing nature of educational research and a critique of postmodernism. Educational Researcher, v. 27, n. 2, mar. 1998.

CUNHA, L. A. Os (Des)caminhos da pesquisa na pós-graduação em educação. In: SEMINÁRIO SOBRE A PRODUÇÃO CIENTÍFICA NOS PROGRAMAS DE PÓS-GRADUAÇÃO EM EDUCAÇÃO. Brasília, MEC/CAPES, 1979. p.3-15.

. Pós-graduação em educação: ponto de inflexão? Cadernos de Pesquisa, n. 77, p. 63-80, maio 1991.

DELLATRE, P. Teoria/modelo. In: ENCICLOPÉDIA EINAUDI. Lisboa: Imprensa Nacional, 1992. p. 223-87.

FONSECA, C. Quando cada caso NÃO é um caso. Revista Brasileira de Educação, n. 19, p. 58-78, jan./abr. 1999.

GATTI, B. A. Pós-graduação e pesquisa em educação no Brasil: 1978-1981. Cadernos de Pesquisa, n. 44, p.3-17, fev. 1983.

. Retrospectiva da pesquisa no Brasil. Revista Brasileira de Estudos Pedagógicos, v. 68, n. 159, p. 279-88, maio-ago. 1987.

GOUVEIA, A. J. Pesquisa educacional no Brasil. Cadernos de Pesquisa, n. I, p. I-48, jul. 1971.

.Pesquisa em educação no Brasil: de 1970 pra cá. Cadernos de Pesquisa, n. 19, p. 759, dez. 1976. 
KENNEDY, M. M. The Connection between research and practice. Educational Researcher, v.26, n. 7, p. 4-12, oct. 1997.

LINCOLN, Y.; GUBBA, E. G. Naturalistic inquiry. London: Sage, 1985.

MARSHALL, C.; ROSSMAN, G. B. Designing qualitative researcher. London: Sage, 1989.

MELLO, G. N. A Pesquisa educacional no Brasil. Cadernos de Pesquisa, n.46, p.67-72, ago. 1983.

MILLES, M. B.; HUBERMAN, M. A. Qualitative data analysis. a source book of new methods. London: Sage, 1984.

PHILLIS, D. C. Subjectivity and objectivity: an objective inquiry. In: EISNER, E.; PESKIN, W. Qualitative inquiry in education. New York: Teachers College Press, 1990. p. 19-37.

POPPER, K. The Logic of the social sciences. The Positivism dispute in German sociology. London: Heinemann, 1976. p. 87-121.

WARDE, M. J. O Papel da pesquisa na pós-graduação em educação. Cadernos de Pesquisa, n. 73, p. 67-75, maio 1990.

YIN, R. K. Case study research: design and methods. London: Sage, 1984. 